\title{
Synthesis of Organic-Inorganic Hybrid Material with a Synergistic Interface as a Release Agent for Free Acid $\beta$-Hydroxy- $\beta$ - Methyl Butyrate
}

\author{
Beatriz A. Andrade-Espinoza $\mathbb{D}^{1},{ }^{1}$ Gregorio G. Carbajal-Arizaga $\mathbb{D}^{2},{ }^{2}$ Selma Rivas-Fuentes $\mathbb{D}{ }^{3}$ \\ Karla Nuño $\left(\mathbb{C}^{4},{ }^{4}\right.$ José Benito Pelayo-Vázquez $\left({ }^{5},{ }^{5}\right.$ and Jenny Arratia-Quijada ${ }^{4}{ }^{4}$ \\ ${ }^{1}$ Departamento de Ciencias de la Salud, Centro Universitario de los Altos, Av. Rafael Casillas Aceves No. 1200, 47600 Tepatitlán \\ de Morelos, Jalisco, Mexico \\ ${ }^{2}$ Departamento de Química, Centro Universitario de Ciencias Exactas e Ingenierías, Blvd. Marcelino García Barragán No. 1421, \\ Esq. Calzada Olímpica, 44430 Guadalajara, Jalisco, Mexico \\ ${ }^{3}$ Departamento de Investigación en Bioquímica, Instituto Nacional de Enfermedades Respiratorias Ismael Cosío Villegas, Calzada de \\ Tlalpan 4502, 14080 Ciudad de México, Mexico \\ ${ }^{4}$ Departamento de Ciencias Biomédicas, Centro Universitario de Tonalá, Av. Nuevo Periférico No. 555, Ejido San José Tateposco, \\ 45425 Tonalá, Jalisco, Mexico \\ ${ }^{5}$ Departamento de Ciencias Básicas y Aplicadas, Centro Universitario de Tonalá, Av. Nuevo Periférico No. 555, Ejido San \\ José Tateposco, 45425 Tonalá, Jalisco, Mexico
}

Correspondence should be addressed to Jenny Arratia-Quijada; jenny.arratia@academicos.udg.mx

Received 27 July 2021; Revised 25 October 2021; Accepted 10 November 2021; Published 6 December 2021

Academic Editor: Ping Xiao

Copyright (c) 2021 Beatriz A. Andrade-Espinoza et al. This is an open access article distributed under the Creative Commons Attribution License, which permits unrestricted use, distribution, and reproduction in any medium, provided the original work is properly cited.

We report the preparation and characterization of a new organic-inorganic hybrid system composed of type-I collagen and $\mathrm{ZnAl}$ layered double hydroxide (LDH) particles loaded with $\beta$-hydroxy- $\beta$-methyl butyrate (HMB) by coprecipitation reaction. X-ray diffraction (peaks well agree with those reported in the literature), infrared spectroscopy (stretching bonds for both organicinorganic compounds), and X-ray photoelectron spectroscopy confirmed the hybrid system retained HMB in the carboxylate form, and a small fraction turned to the acid form. In both cases, the HMB molecules are assembled to the LDH surface. The hybrid compound results in improved thermal stability for HMB and collagen, as shown by thermal analysis. Scanning electron microscopy data reflects different arrangements from LDH sheets with interesting physicochemical properties since $\mathrm{LDH}$ and collagen protect free HMB and make it more bioavailable and functional. In vitro studies as part of high-throughput screening strategies indicated that LDH hybrids reduced cell viability around $75-90 \%$, which is an acceptable viability value because of the L6 cell line susceptibility. However, all new nanomaterials must be carefully analyzed by different toxicity tests because a single test does not evaluate complete physiological compartments.

\section{Introduction}

The latest developments in science and technology have allowed us to manipulate the structure of materials at atomic levels. It makes possible the development of hybrid organicinorganic materials at the nanometric scale. It attracts the attention of researchers in several areas of knowledge such as nutraceuticals [1], electronics [2], optic [3], and the phar- maceutical industry for controlled drug release [4]. In the past two decades, organic-inorganic hybrid materials have reached intensive development. They range from systems in which the association between both components ends in a single hybrid phase to intimate combinations of different organic and inorganic materials. The interaction between organic with inorganic matrixes generates synergistic effects in the new structures, resulting in multifunctional materials 
with unique properties that could improve the physical characteristics from original constituents, even capable of overcoming the structural limitations of conventional materials $[5,6]$. These properties provide a variety of potential applications in multiple fields, especially for pharmaceutical and biomedical areas such as controlledrelease agents for drug delivery [7].

Inorganic supports are currently useful for designing controlled-release drug systems. Among these, layered double hydroxides (LDH) have attracted considerable interest in preparing controlled-release formulations mainly for two reasons: the surface load of the clay mineral and the ability to modify the interlaminar space $[8,9]$. Many organic molecules have combined with these anionic clays, e.g., antioxidants, amino acids, polymers, and vitamins [6, 10-12]. LDH structure has been known since 150 years ago and are formed by stacked brucite-like layers and interlayer regions or galleries. The group of laminar inorganic materials have a general formula $\left[\mathrm{M}_{1-x}{ }^{2+} \mathrm{M}_{x}{ }^{3+}(\mathrm{OH})_{2}\right]^{x+}\left[\mathrm{A}_{x / n}\right]^{n-}$ - $\mathrm{mH}_{2} \mathrm{O}$, where $\mathrm{M}^{2+}$ is a divalent cation, $\mathrm{M}^{3+}$ a trivalent metal cation, $x$ the molar relation of the trivalent cation $\left[\mathrm{M}^{3+} /\left(\mathrm{M}^{2+}+\mathrm{M}^{3+}\right)\right]$, and $\mathrm{A}^{n-}$ an anion with $n$ charge [13, 14]. Their unique structure could be shaped hexagonal or octahedral and consist of metallic hydroxide sheets positively charged on the exterior, a trivalent cation exchanges with an anion generating the excess of positive charge in it [15]. The excess of positive charge is compensated in the interlayer region by water and charge-balancing anions (i.e., ${ }^{-} \mathrm{OH}, \mathrm{Cl}^{-}, \mathrm{SO}_{4}{ }^{2-}, \mathrm{NO}_{3}{ }^{-}$, and $\mathrm{CO}_{3}{ }^{2-}$ ) $[14,16]$. The $\mathrm{A}^{n-}$ provides an anion exchange capability and allows modification through intercalation or functionalization $[13,17]$. Several synthesis methods have been reported in the literature to produce them (i.e., structural reconstruction, coprecipitation, ion exchange hydrothermal, urea hydrolysis, and the sol-gel) [14-16]. The synthesis route represents a crucial step since it affects the crystallinity of the nanoparticles, the capacity of charge, and the yield produced [18]. $\mathrm{LDH}$ synthesis based on $\mathrm{Zn}-\mathrm{Al}$ or $\mathrm{Mg}-\mathrm{Al}$ by the coprecipitation and the ionic exchange methods is suitable to insert bioactive molecules [19] successfully.

Another promising class of materials with great potential as a delivery system is the collagen, a polymeric compound [20]. Collagen is an extracellular fibrous protein representing approximately $25-30 \%$ of the total human body proteins. This protein is present in a higher proportion in tissues such as bone, tendons, skin, and connective tissue [21]. Their hydrolysis produces collagen peptides that are reabsorbed in the small intestine easily, very quickly, and almost intact [22]. It has a helical structure and is composed of polypeptide chains. Besides, it contains abundant functional groups, like $-\mathrm{OH},-\mathrm{NH}_{2}$, and-COOH. All functional groups in their structure can react with some metal ions by adsorptive immobilization. Collagen is the biopolymer most useful for biomedical purposes. It has properties such as biocompatibility, low immunogenicity, polarization, and electrostatic attraction [20,23]. Nevertheless, the potential use of natural collagen is limited because of their reduced thermal stability and enzyme resistance. However, these drawbacks can be overcome through exogenous chemical, physical, or biologi- cal agents capable to modify the molecular structure of collagen [20].

On the other hand, bioactive molecules like $\beta$-hydroxy$\beta$-methyl butyrate (HMB), a leucine derivative metabolite, are intensely interested in nutrition. It has recognized functions in preserving muscle mass in health, disease, and as an ergogenic aid in exercise $[24,25]$. The alkaline oxidation of diacetone-alcohol with sodium hypochlorite allows laboratory separation of HMB. Once obtained, this can be neutralized with hydroxide sodium or calcium hydroxide to form a soluble salt in water [26]. Most of the clinical studies concerning $\mathrm{HMB}$ have been carried out with the use of $\mathrm{HMB}$ in its calcium salt form (Ca-HMB) and, recently, on its free acid form (FA-HMB) (Figure 1). Both presentations have been commercially available as a dietary supplement [27]. However, recent studies have shown that FA-HMB improves bioavailability independent of the way of administration; that is, that FA-HMB improves efficacy through quicker and greater tissue utilization [28]. Despite this, the bioavailability for FA-HMB depends on a high repeated dosage and, it represents a limitation to their use.

An efficient drug carrier must present characteristics, such as low toxicity, high loading capacity, controlled and sustained release, and higher cell uptake [29]. In this context, collagen and LDH meet prerequisites such as low toxicity to perform as drug carriers. LDH also can improve numerous relevant drug properties, such as in vivo precision and stability, improving their solubility, enhancing the drug efficiency, and protecting the "free" drugs [7].

Then, the synthesis of hybrid materials Collagen- $\mathrm{ZnAl}$ $\mathrm{LDH}$ loaded with HMB represents an alternative as a carrier with increased bioavailability for this molecule and could be a future functional food.

Therefore, the increasing use of these materials as carriers for bioactive molecules has promoted the evaluation of the nanomaterials toxicity. In vitro models are helpful to know the toxicological potential that these materials could present.

This work presents the synthesis and characterization of hybrid nanocomposite based on Collagen-ZnAl LDH loaded with HMB. Besides, we carried out a preliminary test of the possible cytotoxic effect these compounds could present on the L6 cell line using the WST-1 toxicity assay.

\section{Material and Methods}

2.1. Material. Calcium 3-hydroxy-3-methylbutyrate hydrate $\left(\mathrm{C}_{10} \mathrm{H}_{18} \mathrm{CaO}_{6} \cdot \mathrm{H}_{2} \mathrm{O}\right)$, molecular weight 274.33 , was purchased at $97 \%$ purity from Alfa Aesar. $\mathrm{Al}\left(\mathrm{NO}_{3}\right)_{3} \cdot 9 \mathrm{H}_{2} \mathrm{O}$ at $98 \%$ with molecular weight 375.13 was purchased from J. T. Baker and used as received; $\mathrm{Zn}\left(\mathrm{NO}_{3}\right)_{2} \cdot 6 \mathrm{H}_{2} \mathrm{O}$ at $99 \%$ with molecular weight 297.47 was purchased from Jalmek and used as received. Type I Collagen, $\mathrm{NH}_{4} \mathrm{OH}$ at $28 \%$, and $\mathrm{NaOH}$ were purchased from Golden Bell. WST-1 (tetrazolium/formazan salts) and PBS were purchased from Sigma-Aldrich. Dulbecco's Modified Eagle's Medium was purchased from Gibco. L6 cells (rat myofibroblast cell line, CRL-1458) were acquired from ATCC ${ }^{\circledR}$. Analytical grade reagents and deionized water were used in all experiments. 


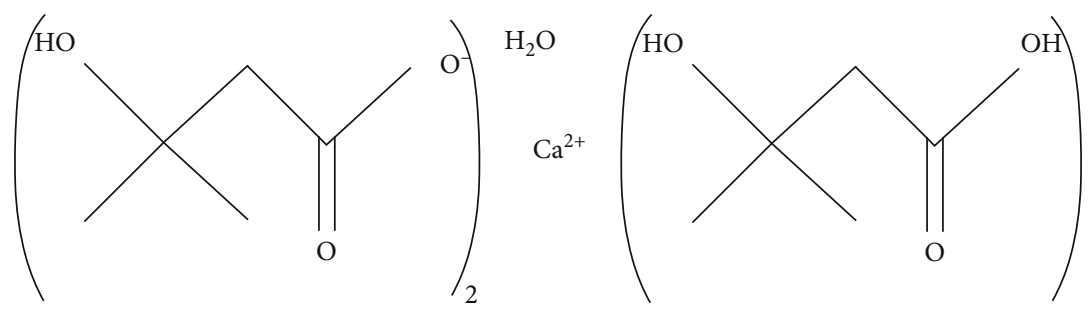

(a)

(b)

Figure 1: Chemical structures of (a) calcium salt (CaHMB), and (b) free acid form of $\beta$-hydroxy- $\beta$-methylbutirate (FA-HMB).

2.2. Synthesis LDH. The LDH was prepared by a controlled$\mathrm{pH}$ coprecipitation technique of the metal nitrate salts at room temperature, similar to previously reported [30]. $\mathrm{LDH}$ was prepared with a $\mathrm{Zn}: \mathrm{Al}$ molar ratio of $3.75: 1$. Briefly, a mixture with $15 \mathrm{mmol}$ of $\mathrm{Zn}\left(\mathrm{NO}_{3}\right)_{2}, 4 \mathrm{mmol}$ of $\mathrm{Al}\left(\mathrm{NO}_{3}\right)_{3}$, and $100 \mathrm{~mL}$ of decarbonated water was stirred in a griddle, and then, the $\mathrm{pH}$ was adjusted to 8 by adding an $\mathrm{NH}_{4} \mathrm{OH}(6 \%)$ solution. The precipitate was then aged for $24 \mathrm{~h}$ under stirring at $25^{\circ} \mathrm{C}$, and it was recovered by centrifugation, washed four times with deionized water, and dried at $25^{\circ} \mathrm{C}$.

2.3. Synthesis of Hybrid LDH Derivates. Direct precipitation of the hybrid materials Collagen-ZnAl/HMB was carried out briefly dissolving $100 \mathrm{mmol}$ of HMB in $10 \mathrm{~mL}$ of decarbonated water. Subsequently, we added dropwise $1 \mathrm{M} \mathrm{NaOH}$ solution to separate $\mathrm{Ca}(\mathrm{II})$ from HMB salt, then the solution was centrifuged, and the supernatant was reserved to use later. Then, $15 \mathrm{mmol}$ of $\mathrm{Zn}\left(\mathrm{NO}_{3}\right)_{2}$ and $4 \mathrm{mmol}$ of $\mathrm{Al}\left(\mathrm{NO}_{3}\right)_{3}$ were dissolved in $30 \mathrm{~mL}$ of decarbonated water; the supernatant with $\mathrm{HMB}$ was subsequently added dropwise to the salt solution. Finally, $100 \mathrm{mmol}$ of collagen type I was dissolved into $60 \mathrm{~mL}$ of decarbonated water, and then, the solution with $\mathrm{ZnAl} / \mathrm{HMB}$ was added slowly. The $\mathrm{pH}$ of the solution was adjusted to 8 with $\mathrm{NH}_{4} \mathrm{OH}(6 \%)$. The precipitate was then aged for $24 \mathrm{~h}$ under stirring at $25^{\circ} \mathrm{C}$, and it was recovered by filtration, washed four times with deionized water, and dried at $25^{\circ} \mathrm{C}$.

Further, samples of $\mathrm{ZnAl} / \mathrm{HMB}$ and Collagen-ZnAl were prepared following the same steps to prepare the hybrid composite but adding only the HMB or collagen solution, respectively.

2.4. Characterization Techniques. The diffraction analyses were carried on a PANalytical diffractometer model EMPYREAN using Cu-K $\alpha$ radiation $\left(1.5404 \AA\right.$ ), a step of $0.02^{\circ}(2 \theta)$, and a time of $40 \mathrm{~s} / \mathrm{step}$; the potential and the current were $45 \mathrm{kV}$ and $30 \mathrm{~mA}$, respectively.

The infrared analyses were performed in reflectance mode (FTIR) using a Thermo Scientific spectrometer, model NICOLET iS5 iD5 ATR. Spectra were recorded in the range of $4000-400 \mathrm{~cm}^{-1}$ with a resolution of $4 \mathrm{~cm}^{-1}$ and an accumulation of 16 scans.

The phase transition thermograms were recorded with a DSC Q100 differential scanning calorimeter from TAInstruments in a dynamic nitrogen atmosphere. The sample with a mass of about $\sim 4 \mathrm{mg}$ was placed in sealed aluminum pans. The heat increase used for this experiment was $10^{\circ} \mathrm{C} \mathrm{min}^{-1}$ in a temperature range from 0 to $400^{\circ} \mathrm{C}$.

SEM morphology studies were conducted in a JEOL JSM $5400 \mathrm{LV}$ scanning electron microscope. For this purpose, the powder samples were placed on double-sided carbon tape. The images were obtained with a potential of $15 \mathrm{kV}$.

The synthesized LDH and their composites were analyzed by the X-ray photoelectron spectroscopy (XPS) technique to elucidate chemical composition and the absence of $\mathrm{Ca}$ from $\mathrm{HMB}$ salts. The system consisted of an XR $50 \mathrm{M}$ monochromatic Al $\mathrm{K} \alpha 1(\mathrm{hv}=1468.7 \mathrm{eV}) \mathrm{X}$ ray source and a Phoibos 150 spectrometer with a onedimensional detector 1D-DLD provided by SPECS (Berlin, Germany). Samples were mounted on a steel sample holder using a recovering to complete elemental analysis, including the carbon.

Prepared samples were dried in a vacuum oven at room temperature for $48 \mathrm{~h}$ before being introduced to the prechamber. Measurements were collected with a resolution of $0.5 \mathrm{eV}$.

2.5. Cytotoxicity Assay. Cytotoxicity assay was performed using the colorimetric WST-1 (tetrazolium/formazan salts). L6 cells (rat myofibroblast cell line) were cultured in Dulbecco's Modified Eagle's Medium (with $25 \mathrm{mM}$ glucose, $2 \mathrm{mM}$ L-glutamine, $1 \mathrm{mM}$ sodium pyruvate, and $10 \%$ of fetal bovine serum). The cells were cultured in an atmosphere containing $5 \% \mathrm{CO}_{2}$ atmosphere at $37^{\circ} \mathrm{C}, 24 \mathrm{~h}$ before the assay; $2.5 \times 10^{3}$ of L6 cells (in $100 \mu \mathrm{L}$ ) were seeded per well on 96-well plates. After $24 \mathrm{~h}$, cells were treated with ZnAl molar ratio 3.75: 1; ZnAl/HMB; Collagen-ZnAl; Collagen-ZnAl/HMB; $\mathrm{HMB}$; and type I Collagen as a control during 24 or $48 \mathrm{~h}$. All experiments were run in triplicate, and cells in Dulbecco's modified Eagle's medium were used as the positive control. At the end of treatment, the medium was removed, and each well was washed two times with PBS 1X (phosphate-buffered saline). Then, $100 \mu \mathrm{L}$ of media with $10 \%$ WST-1 solution was added and incubated for $1.5 \mathrm{~h}$ at $37^{\circ} \mathrm{C}$ under a $5 \% \mathrm{CO}_{2}$ atmosphere for each well, allowing the reduction reaction from WST-1 to formazan by viable cells. Finally, the 96 -well plate was measured by recording the absorbance at $450 \mathrm{~nm}$ using a plate reading spectrophotometer.

Statistical analysis to determine a significant difference between treated groups was tested by ANOVA and Tukey post hoc test with $p \leq 0.05$. 


\section{Results and Discussion}

3.1. X-Ray Diffraction. The X-ray diffraction patterns of the samples were analyzed to investigate the formation of the layer structure of $\mathrm{LDH}$ and $\mathrm{HMB}$ intercalation into the lamellar host structure (Figure 2). The XRD pattern of the $\mathrm{ZnAl} \mathrm{LDH} \mathrm{molar} \mathrm{ratio} \mathrm{of} \mathrm{3.75:1} \mathrm{exhibits} \mathrm{sharp} \mathrm{and} \mathrm{intense}$ peaks. The profile of the pristine $\mathrm{ZnAl} \mathrm{LDH}$ is coherent with the formation of the nitrate-containing layered particles, and the profile is constant in all the samples. It indicates that the composites result from an assembly of $\mathrm{HMB}$ or collagen over the surfaces of the particles. In this way, the diffractograms are the mere result of the profile from the inorganic particles and the amorphous fraction of organic matter. The most intense reflections of $\mathrm{ZnAl} \mathrm{LDH}$ at low values of $2 \theta 9.82,19.74,33.63$, and 60.15 correspond to the planes (003), (006), (009), and (110) characteristic for these lamellar compounds (Figure 2). These are similar to the profile recorded in ICDD card no. 380486, reporting the $\mathrm{Zn}_{3} \mathrm{~A}$ $1(\mathrm{OH})_{8}\left(\mathrm{CO}_{3}\right)_{0.5} \cdot 2 \mathrm{H}_{2} \mathrm{O}$ packed in a rhombohedral cell with space group R-3 m and cell parameters $a=3.1$ and $c=22.8$ angstroms $(\AA)$. Using the diffractogram of the pristine ZnAlLDH as a starting point to analyze the structure, the reflection at the lowest angle appears at 9.82 degrees. Using the Bragg equation reported elsewhere, the interplanar distance was calculated, equal to $9.0 \AA$. This distance comprises the layer thickness and the interlayer space, which depends on the size of the intercalated ion. In this case, the $9.0 \AA$ is in agreement with the presence of nitrate ions $[31,32]$. The $c$ parameter is calculated using the $d_{(003)}$ basal distance as $27 \AA$ [33]. The basal distance in our product is larger than the reported in the ICDD card. It is a coherent fact considering that the layers of nitrate intercalated LDH are bonded with weaker force than carbonate. This evidence indicates that our procedure favored the intercalation of nitrate ions instead of carbonate. In the hybrid compounds synthesized, the intensity decreased for the (003) and (006) peaks, while the widening increased. It indicates a lower crystallinity or a very probable reduction of the particle size.

Nevertheless, the general aspect of XRD patterns of the hybrid samples (ZnAl/HMB, Collagen-ZnAl, and Collagen$\mathrm{ZnAl} / \mathrm{HMB}$ ) is comparable with pure $\mathrm{LDH}$. Regarding the Collagen-LDH pattern, supplementary reflection is noted (indexed by an asterisk in Figure 2). Although the pure collagen is almost amorphous, it produces a most intense signal at 22 (2 theta) degrees, and two signals with lower intensity appear at 8 and 40 (2 theta) degrees [34]. The reflection at 22 and 40 ( 2 theta) degrees confirms the presence of collagen because it is similar to pure collagen. In the Collagen$\mathrm{ZnAl} / \mathrm{HMB}$ sample, these signals are not present, indicating that collagen is absent. However, as infrared data will demonstrate, collagen exists, the lack of collagen signals in the XRD data suggests a lower collagen content, or the structure became utterly amorphous. Since, we observed the reflection around 60.22 degrees $2 \theta$ attributed to the (110) plane for all of the samples, indicating an assembly of LDH and hybrid structures with good crystallinity. No peaks were shifting when we compared the $\mathrm{ZnAl} \mathrm{LDH,} \mathrm{ZnAl/HMB}$, and Colla-

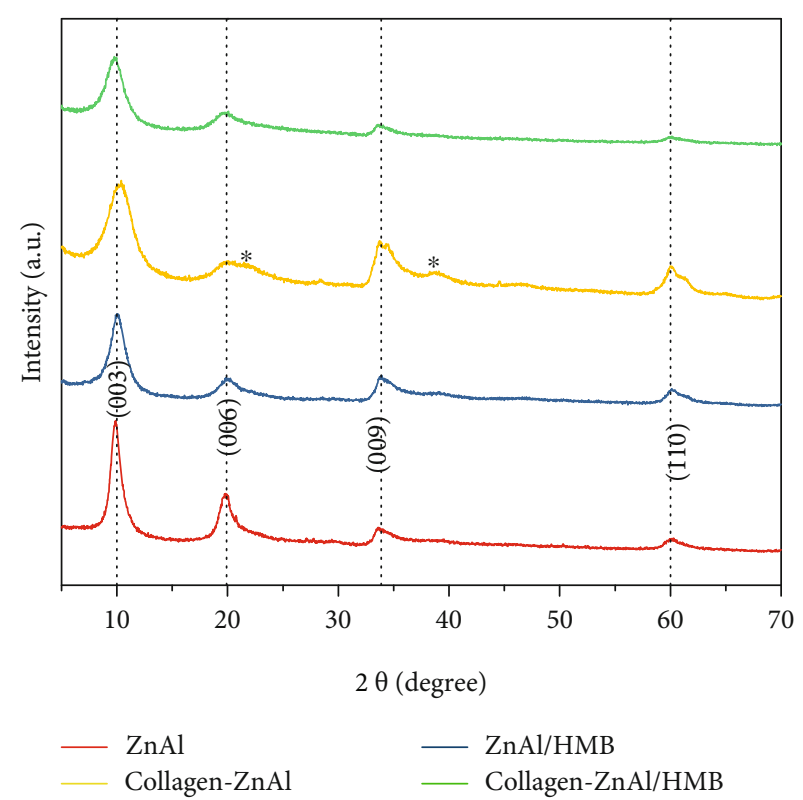

FIgure 2: X-ray diffraction patterns of $\mathrm{ZnAl} \mathrm{LDH,} \mathrm{ZnAl/HMB,}$ Collagen- $\mathrm{ZnAl}$, and Collagen - $\mathrm{ZnAl} / \mathrm{HMB} .{ }^{*}$ Indicates collagen reflections.

gen- $\mathrm{ZnAl} / \mathrm{HMB}$ diffractograms. It indicates that $\mathrm{HMB}$ never intercalated between the LDH layers.

On the other hand, results in Figure 2 for the $\mathrm{ZnAl} /$ HMB sample indicate that HMB does not alter the layered structure of $\mathrm{LDH}$. We observed something similar in the Collagen-ZnAl and Collagen-ZnAl/HMB profiles. Here, collagen incorporation did not modify the diffraction pattern corresponding to LDH. This result confirms that the synthesis method proposed was efficient in obtaining a crystalline hybrid.

3.2. Infrared Spectroscopy. FTIR analysis from the $\mathrm{ZnAl}$ LDH sample, ZnAl/HMB, Collagen-ZnAl, and Collagen$\mathrm{ZnAl} / \mathrm{HMB}$ hybrids are compared and shown in Figure 3. All patterns exhibit principal fold signals due to the different functional groups present. The FTIR spectrum of $\mathrm{ZnAl} \mathrm{LDH}$ shows a broad and strong absorption band centered at $3412 \mathrm{~cm}^{-1}$. This signal is a characteristic feature for all the hydrotalcite-type materials. It corresponds to $\mathrm{OH}$ stretching vibration in interlayer space and the physically adsorbed water molecules [35]. After adsorption of HMB, collagen, or both, the $\mathrm{OH}$ band becomes broad. It indicates that hydroxyl groups in the surface of the layers form more hydrogen bonds, likely with $\mathrm{HMB}$ and functional groups present in collagen used in the experiments. The bending vibration of the interlayer water molecule $\mathrm{H}-\mathrm{O}-\mathrm{H}$ appears as a band at $\sim 1673 \mathrm{~cm}^{-1}[36,37]$. The strong band at $1373 \mathrm{~cm}^{-1}$ is due to the symmetric vibration of the interlayer nitrate anion from $\mathrm{ZnAl} \mathrm{LDH} \mathrm{[38].} \mathrm{Bands} \mathrm{observed} \mathrm{in} \mathrm{the}$ lower frequency below $750 \mathrm{~cm}^{-1}$ are associated with lattice vibration modes corresponding to $\mathrm{M}-\mathrm{O}(\mathrm{M}=\mathrm{Al}, \mathrm{Zn})$ in the LDH sheets [30]. In Figure 3, spectra of Collagen- $\mathrm{ZnAl}$ and Collagen-ZnAl/HMB samples show the absorption bands characteristic for LDH. However, we can observe that 


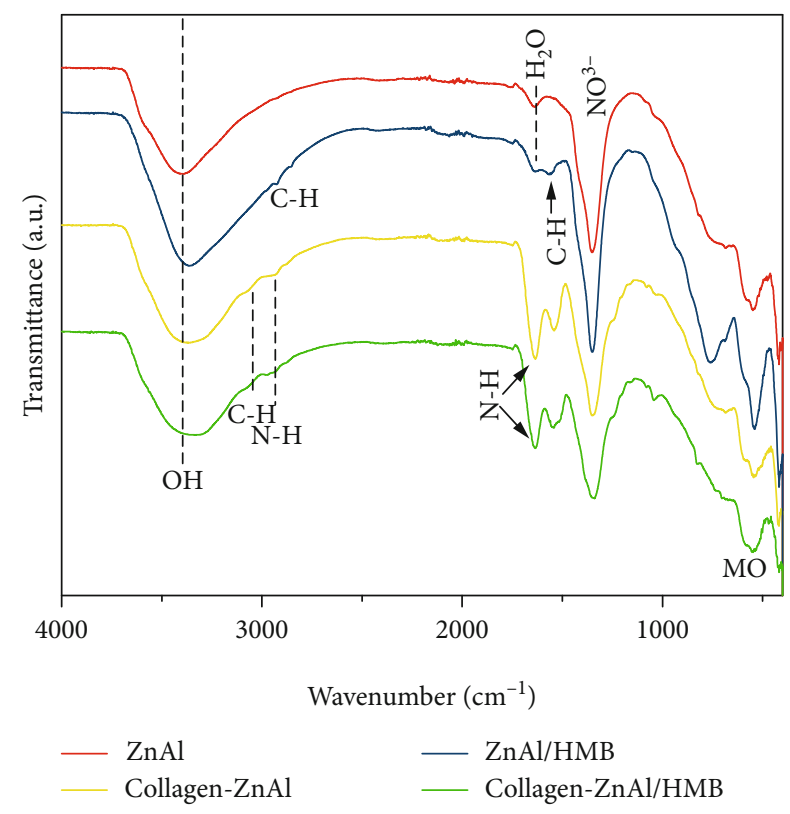

Figure 3: Infrared spectrum of ZnAl LDH, ZnAl/HMB, Collagen$\mathrm{ZnAl}$, and Collagen-ZnAl/HMB.

the vibration band at $1814 \mathrm{~cm}^{-1}$ gets remarkable widening and enhancement, ascribing to a broad and clear $\mathrm{C}=\mathrm{O}$ stretching vibration associated with amide $\mathrm{I}$. It is the band most important for studying high-order structure of proteins [37], indicative of effective chemical adsorption of collagen. In particular, NH stretching bands and bending vibration at 3119 and $1721 \mathrm{~cm}^{-1}$ are due to the amide II of collagen [36, 37]. The vibrational frequencies of $\mathrm{C}-\mathrm{H}$ and $\mathrm{N}-\mathrm{H}$ fragments present similar values. Then, their vibrational stretching produces overlapping in the $3100 \mathrm{~cm}^{-1}$ region [39]. ZnAl/HMB and Collagen-ZnAl/HMB exhibit some characteristic absorption peaks at $3152 \mathrm{~cm}^{-1}$ and $1816 \mathrm{~cm}^{-1}$ of $\mathrm{HMB}$, indicating the presence of $\mathrm{HMB}$ molecules on the surface $\mathrm{ZnAl}$ nanohybrids. To demonstrate that these spectral variations are induced by the HMB molecule, another experiment was carried out (data are shown in supplementary material S1). The results reflect that an increase in the amount of $\mathrm{HMB}$ causes an increase in the signals mentioned in Figure 3 as corresponding to HMB.

3.3. Differential Scanning Calorimetry. Thermoanalytical measurements for $\mathrm{ZnAl} \mathrm{LDH}$ and hybrid compounds as a function of temperature at a heating rate of $10^{\circ} \mathrm{C} \mathrm{min}^{-1}$ were recorded and reported in Figure 4 . We observed that the thermal degradation process of pure LDH (Figure 4 curve a) implies two main transition stages: (i) a reversible phase without lamellar structure collapse; a partial dehydroxylation from LDH layers occurs with an endothermic peak at around $152^{\circ} \mathrm{C}$; (ii) a decomposition of hydroxides and consequently the elimination of interlayer anion, denoted by signals ranging from 218 to $293^{\circ} \mathrm{C}$ [40]. The decomposition temperature and elimination of interlayer anion are higher than pure $\mathrm{LDH}$ after $\mathrm{HMB}$ adding into it (Figure 4(b)). It indicates $\mathrm{ZnAl} / \mathrm{HMB}$ is more stable to thermal degradation than $\mathrm{HMB}$ pure degradation $\left(274^{\circ} \mathrm{C}\right)$ (supplemental Figure S2).
Proteins such as collagen contain bonds that maintain the secondary and tertiary structure, which break down with temperature increments. The collagen triple helix is unwinding and leaving single chains. This point is known as the denaturation phenomenon different from degradation, which implies that the breaking of peptide bonds leads to the formation of an amorphous polymer known as gelatin [41]. The first transition temperature observed at $67^{\circ} \mathrm{C}$ (Figure 4(c)) corresponds to the denaturing temperature of type I collagen due to increased temperature. That phenomenon leads to an amorphous polymer (gelatin) formation at $148^{\circ} \mathrm{C}$ [42]. Finally, on increasing the temperature above $290^{\circ} \mathrm{C}$, degradations of the material occur. The Collagen$\mathrm{ZnAl} / \mathrm{HMB}$ structure shows a weak endothermic process at $164.95-221.6^{\circ} \mathrm{C}$. It is followed by the combustion of the hybrid, reflected as an intense exothermic peak produced in the DSC profile (Figure $4(\mathrm{~d})$ ) centered at $252.4^{\circ} \mathrm{C}$. Then, the hybrid materials $\mathrm{ZnAl} / \mathrm{HMB}$ and Collagen- $\mathrm{ZnAl}$ showed high thermal stability, overcoming the main drawbacks for their natural usage.

3.4. Scanning Electron Microscopy. The SEM image shows that synthesized ZnAl LDH (Figure 5(a)) exhibits typical aggregates for this class of materials, displaying a grouped plate of hexagonal particles with a flake aspect. After introducing HMB (Figure 5(b)), the nanosheets become interconnected, forming a network-like array with noticeable ripples and corrugations. The Collagen-ZnAl sample shows sheets relatively disordered and parallel stacking (Figure 5(c)), where sheets grow vertically on the collagen matrix. The hybrid sample of Collagen-ZnAl/HMB in Figure 5(d) exhibits a severe agglomeration of the platelets. The intense interaction between proper collagen molecules and between collagen and LDH sheets has led to the hard clustering of the platelets providing compactness to the resulting material.

3.5. X-Ray Photoelectron Spectroscopy. XPS analysis was performed, focusing on the surface composition of hybrid $\mathrm{ZnAl} / \mathrm{HMB}$ nanocomposite.

This sample was analyzed to corroborate the elimination of Ca from HMB salt to produce a hybrid with $\mathrm{HMB}$ in its pure form or FA-HMB. XPS results for LDH, HMB (treated by precipitation reaction), and $\mathrm{ZnAl} / \mathrm{HMB}$ samples indicated that precipitation reaction was very efficient to $\mathrm{Ca}$ elimination from HMB salt. However, a small signal on the survey XPS is appreciated (Figure 6). Indeed, this separation method allows us to get a free form to HMB.

The results of elemental identification and quantification for XPS spectra (Table 1) show the characteristic peaks of $\mathrm{Al} 2 \mathrm{p}$ and $\mathrm{Zn} 2 \mathrm{p}$ electrons and indicate the presence of these elements in $\mathrm{LDH}$ structure with the principal oxidation states of $\mathrm{Al}^{3+}$ and $\mathrm{Zn}^{2+}$ for both spectra, $\mathrm{ZnAl}$ and $\mathrm{ZnAl}$ / $\mathrm{HMB}$ samples [43]. The atomic ratio of $\mathrm{ZnAl}$ changed from 3.8 in the $\mathrm{ZnAl}$ to 4.2 in the $\mathrm{ZnAl} / \mathrm{HMB}$, which is not a significant change, maintaining the structural morphology of the sheets without considerable changes. These spectra signals also show the presence of $\mathrm{O}$ and $\mathrm{C}$, corresponding to hydroxyl sheets from $\mathrm{LDH}$ and organic composition, respectively. The atomic ratio of $\mathrm{O} / \mathrm{C}$ in $\mathrm{ZnAl}$ and $\mathrm{ZnAl} /$ 


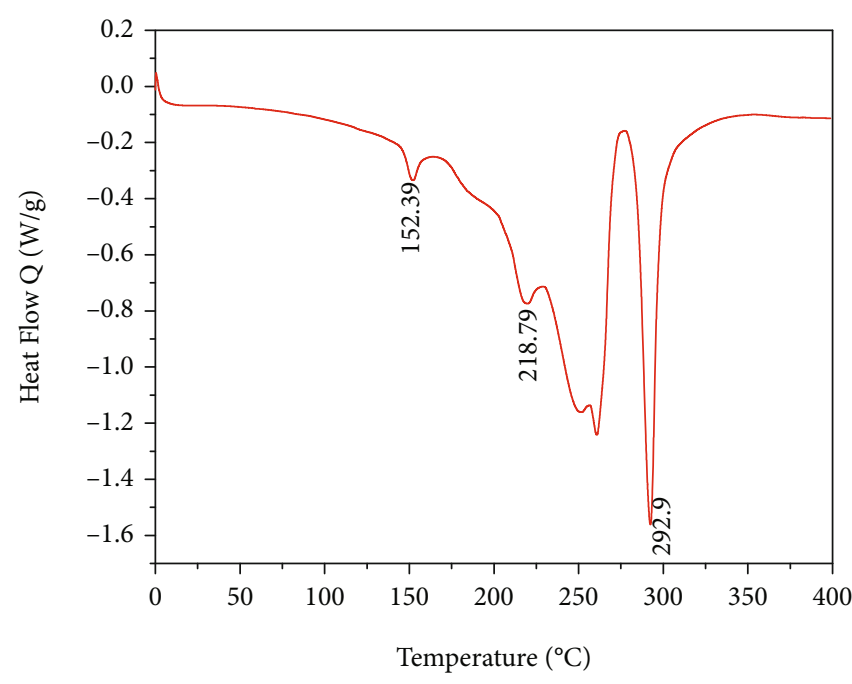

(a)

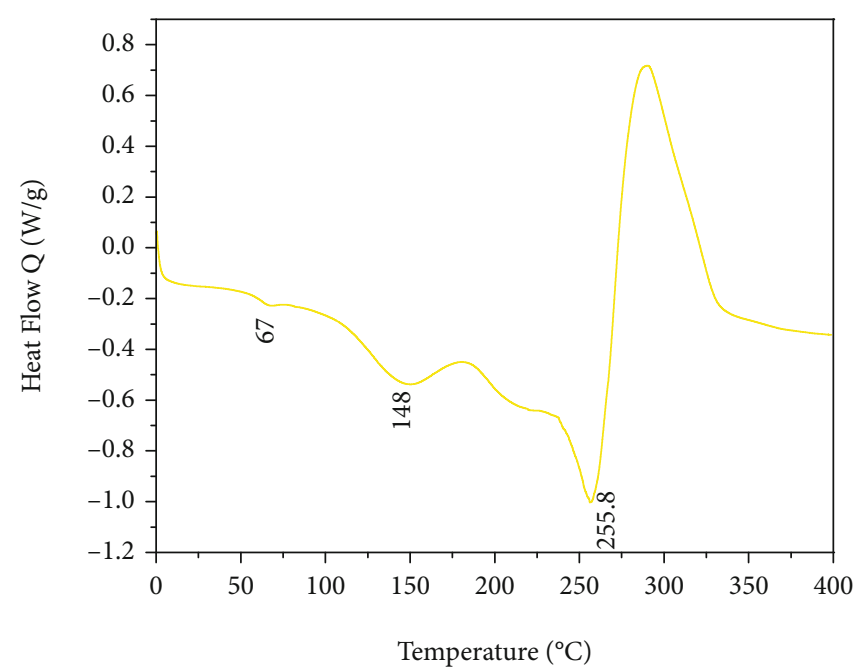

(c)

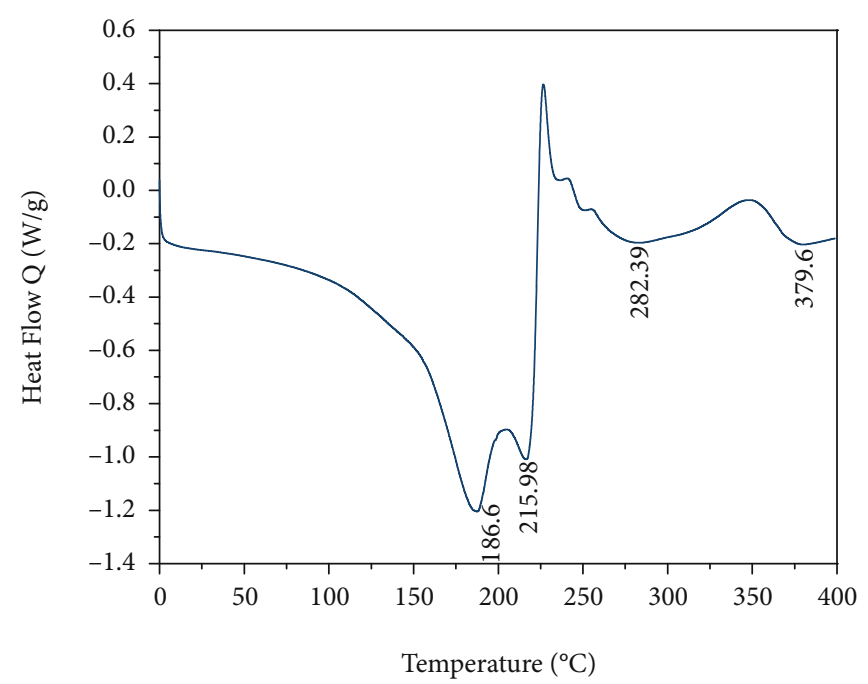

(b)

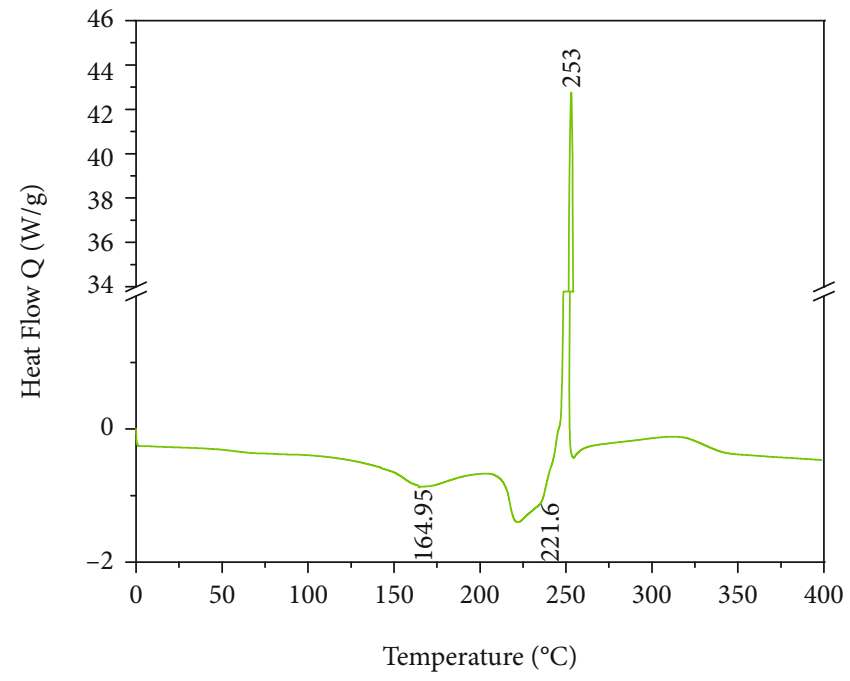

(d)

Figure 4: DSC thermogram of (a) ZnAl LDH, (b) ZnAl/HMB, (c) Collagen-ZnAl, and (d) Collagen-ZnAl/HMB.

HMB is similar to that reported for this type of $\mathrm{ZnAl} \mathrm{LDH}$ [43]. The $\mathrm{Ca}$ and $\mathrm{N}$ signal corresponds to residual calcium and nitrates by using these salts as precursors of the HMB pure and $\mathrm{LDH}$, respectively. The chemical state proposed for elements as $\mathrm{C}$ and $\mathrm{O}$ is confirmed, as we showed previously in IR spectra Figure 3.

3.6. Cytotoxicity Assay. The potential application of newly developed nanomaterials as carriers of substances depends on their biocompatibility, among other aspects. Therefore, all designed nanomaterials should be subjected to toxicological studies. The in vitro toxicity test on cell lines is essential for preclinical evaluations. Currently, several approaches are helpful to assess the toxic effects of nanomaterials by exposure or direct contact. Among them, the tetrazolium salt reduction assays [44]. Tetrazolium-based assays are used because they are sensitive, cheap, and easy to handle [45]. As a preliminary test, we perform an assay to evaluate the possible toxic effect using the tetrazolium-based salt WST-
1. $\mathrm{ZnAl} \mathrm{LDH}$ and the hybrid combinations $\mathrm{ZnAl} / \mathrm{HMB}$, Collagen-ZnAl, and Collagen-ZnAl/HMB were evaluated in a dose-dependent manner in the L6 cell line as a model to represent the physiological muscle compartment. Figure 7 shows the viability of L6 cells after exposure to $\mathrm{LDH}$ and LDH hybrid compounds, compared with the effect of pure HMB and Collagen after 24 and $48 \mathrm{~h}$ of incubation. Cellular viability decreases at concentrations from 0.37 to $3.3 \mu \mathrm{g} / \mathrm{mL}$ as the concentration of hybrid compounds increases. All treatments with collagen or HMB maintain and increase the mean viability $(80-115 \%)$, respectively, which indicates a healthy proliferation state at 24 and $48 \mathrm{~h}$ of incubation (Figures $7(a)$ and $7(b)$ ).

Furthermore, we observed a significant difference $(p \leq 0.0001)$ between HMB and collagen treatments to materials $\mathrm{ZnAl}, \mathrm{ZnAl} / \mathrm{HMB}$, and Collagen-ZnAl, whereas the hybrid Collagen-ZnAl/HMB did not show a difference at the lowest concentration; it suggests that the organic compounds could have a protective effect over the cells. 


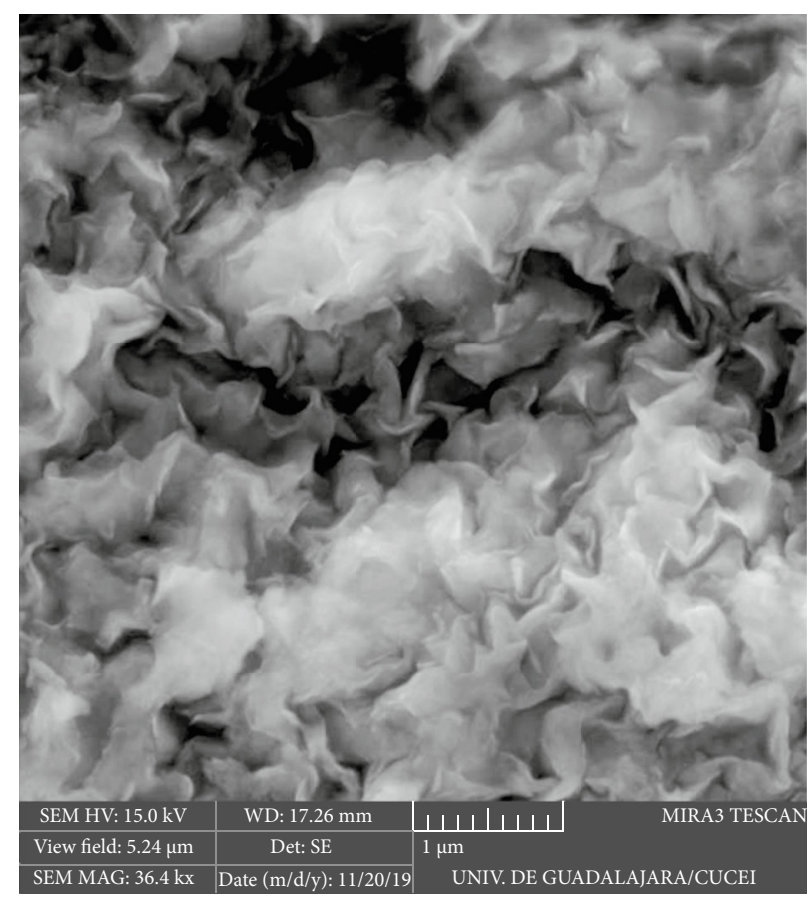

(a)

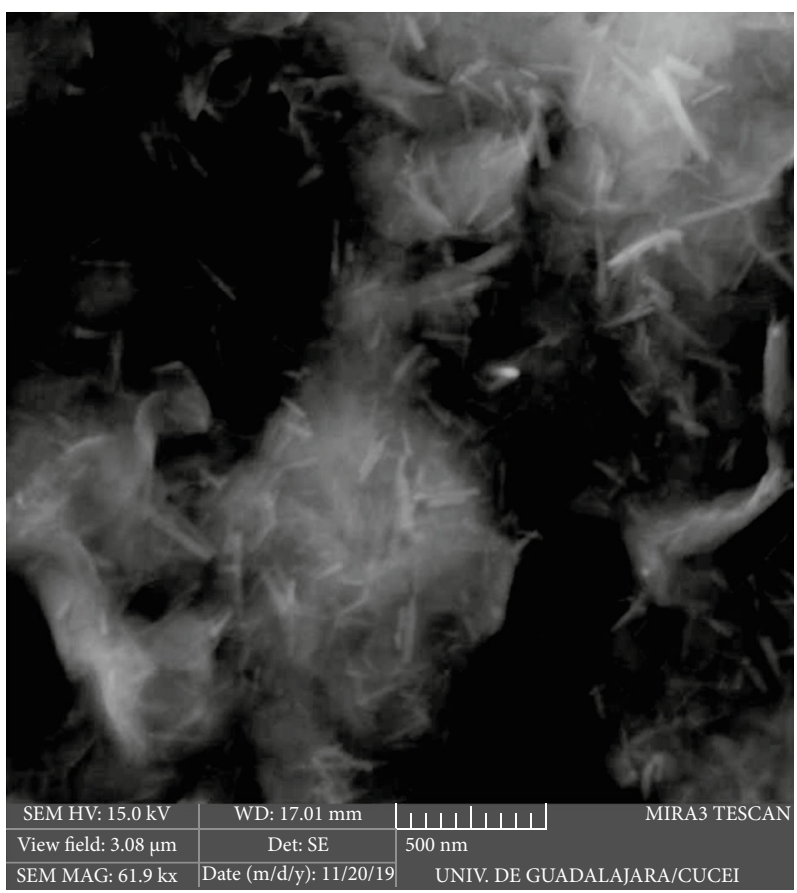

(c)

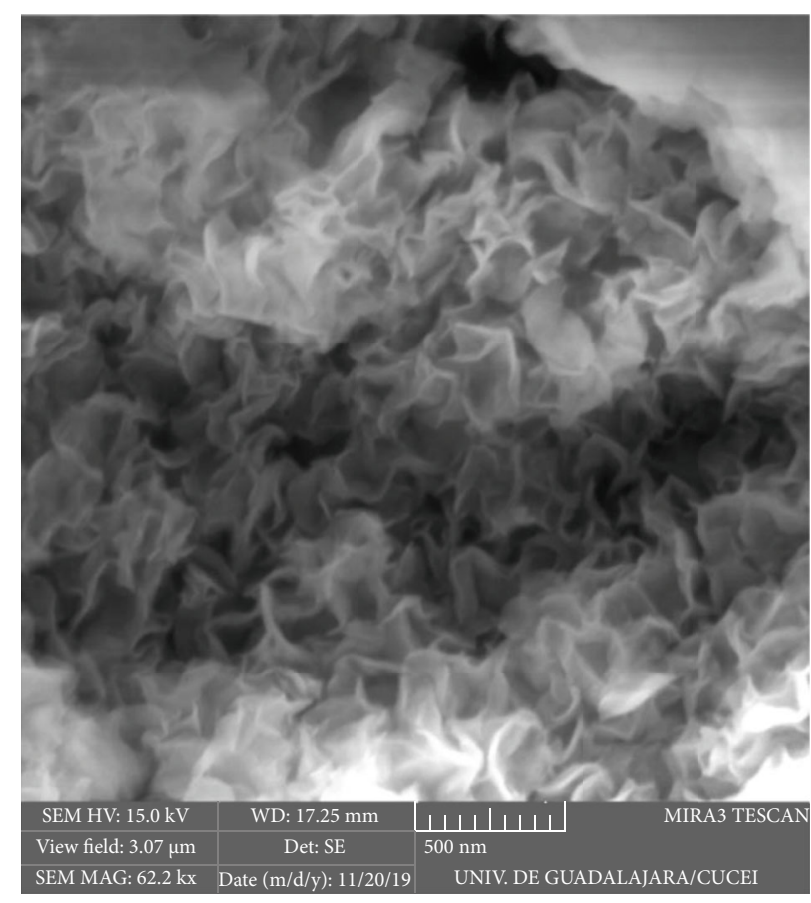

(b)

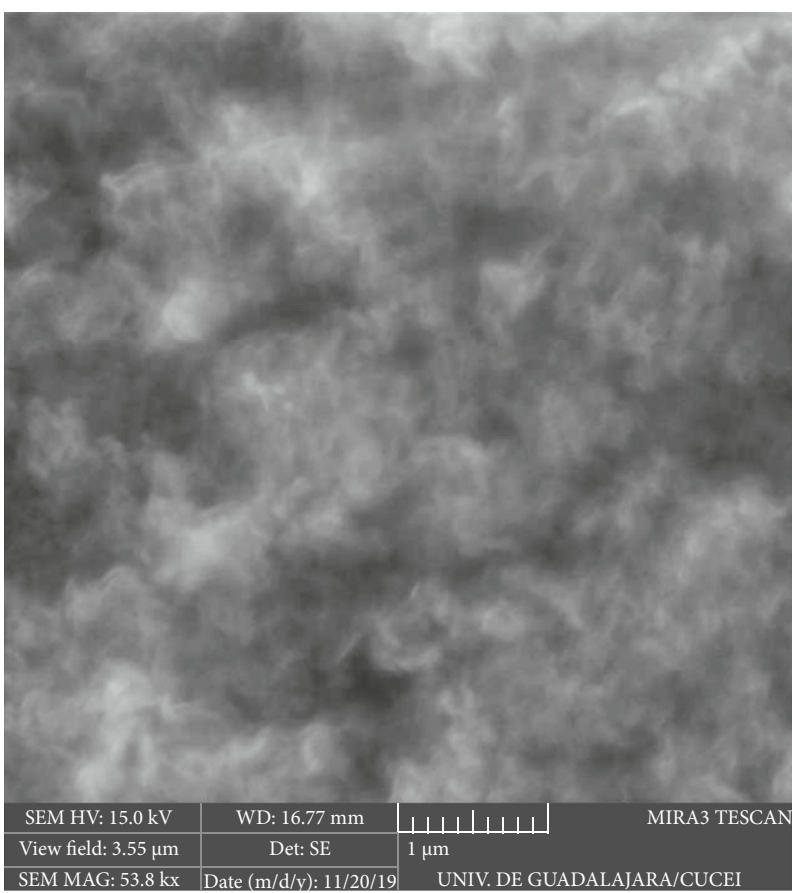

(d)

Figure 5: SEM images of (a) ZnAl, (b) ZnAl/HMB, (c) Collagen-ZnAl, and (d) Collagen-ZnAl/HMB.

Therefore, the observed toxicity is promoted by the LDH nanomaterial in this cell line. The results of the toxicity test show a significantly reduced cell viability in all treatments involved with $\mathrm{ZnAl}$ nanomaterials, and it depends on concentration and incubation period (Figures $7(\mathrm{a})$ and $7(\mathrm{~b})$ ). The cell viability decreased at $10 \%$ when treated with a $10 \mu \mathrm{g} / \mathrm{mL}$ concentration or upper (data not shown). These results contrast to other studies that report no toxic effects of the LDH in cell lines like the G-292 osteoblasts and in the L-132 human lung cells. Inclusively recommend the $\mathrm{LDH}$ as suitable for implants and as promising candidates for developing inorganic delivery systems [35, 46]. Other cellular responses to $\mathrm{LDH}$ nanomaterials have been explored using different model cell lines. Their data have shown a low level of cytotoxicity [9, 36, 38, 47, 48]. In particular, the in vitro toxicity results on the L6 cell line 


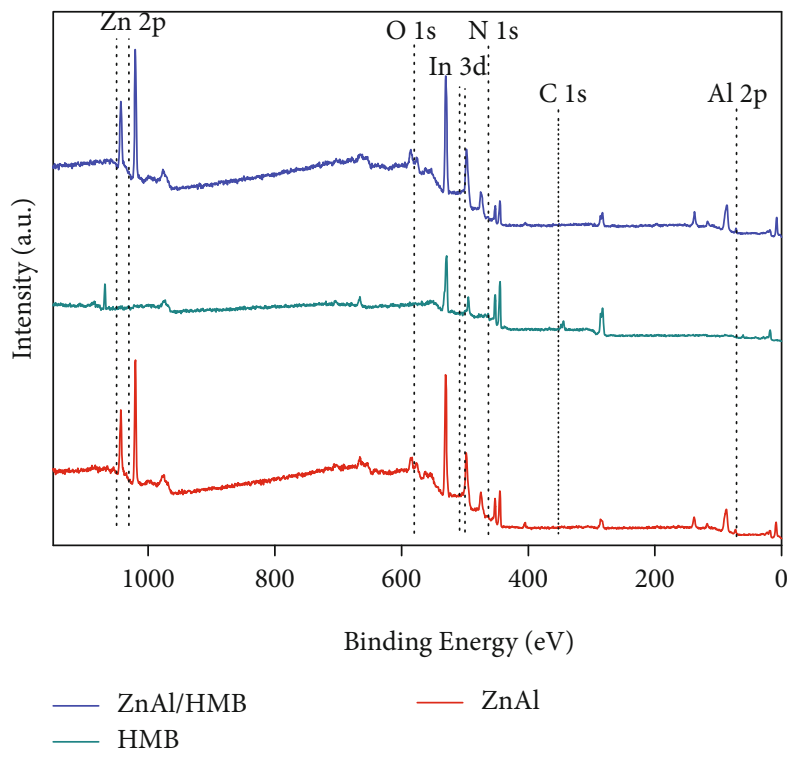

FIGURE 6: XPS analysis focused on the surface composition of hybrid ZnAl/HMB nanocomposite.

TABLE 1: XPS quantitative results for $\mathrm{HMB}, \mathrm{ZnAl}$, and $\mathrm{ZnAl} / \mathrm{HMB}$ (BE values are corrected with contamination carbon as reference at $284.60 \mathrm{eV})$.

\begin{tabular}{|c|c|c|c|c|}
\hline Peak & $\mathrm{BE}$ & FWHM & Atomic (\%) & Chemical state \\
\hline \multicolumn{5}{|l|}{$H M B$} \\
\hline C1s A & 284.5 & 1.7 & 25.7 & $\mathrm{C}-\mathrm{C}$ \\
\hline $\mathrm{C} 1 \mathrm{~s} \mathrm{~B}$ & 286 & 1.7 & 15.7 & $\mathrm{C}-\mathrm{O}$ \\
\hline $\mathrm{C} 1 \mathrm{~s} \mathrm{C}$ & 288.3 & 1.7 & 21.6 & Carboxyl O-C=O \\
\hline O1s A & 531.3 & 1.9 & 25.2 & $\mathrm{OH}$ \\
\hline O1s B & 532.8 & 1.9 & 12.7 & Adsorbed $\mathrm{H}_{2} \mathrm{O}$ \\
\hline O1s C & 535.2 & 1.9 & 6.6 & Carboxyl O-C=O \\
\hline $\mathrm{Na} 1 \mathrm{~s}$ & 1070.9 & 1.9 & 11.9 & $\mathrm{Na}^{+}$ \\
\hline \multicolumn{5}{|l|}{$\mathrm{ZnAl}$} \\
\hline C1s A & 284.5 & 2.2 & 6.6 & $\mathrm{C}-\mathrm{C}$ \\
\hline $\mathrm{C} 1 \mathrm{~s} \mathrm{~B}$ & 287.5 & 2.2 & 5.5 & $\mathrm{C}-\mathrm{O}$ \\
\hline O1s A & 530.1 & 1.9 & 5.8 & Oxides \\
\hline O1s B & 531.6 & 1.9 & 41.6 & $\mathrm{OH}$ \\
\hline O1s C & 533.2 & 1.9 & 9.6 & Nitrates \\
\hline N1s & 406.7 & 1.8 & 2.4 & Nitrates \\
\hline $\mathrm{Zn} 2 \mathrm{p}$ & 1021.4 & 2.5 & 22.5 & $\mathrm{Zn}^{2+}$ \\
\hline $\mathrm{Al} 2 \mathrm{p}$ & 73.9 & 2.2 & 5.9 & $\mathrm{AlO}(\mathrm{OH})$ \\
\hline \multicolumn{5}{|c|}{$\mathrm{ZnAl/HMB}$} \\
\hline C1s A & 284.5 & 2.6 & 9.4 & $\mathrm{C}-\mathrm{C}$ \\
\hline $\mathrm{C} 1 \mathrm{~s} \mathrm{~B}$ & 287.7 & 2.6 & 5.5 & $\mathrm{C}-\mathrm{O}$ \\
\hline O1s A & 530.5 & 1.9 & 17.2 & Oxides \\
\hline O1s B & 532 & 1.9 & 33.5 & $\mathrm{OH}$ \\
\hline O1s C & 533.4 & 1.9 & 3.6 & Nitrates \\
\hline N1s & 404.5 & 2.7 & 1.1 & Nitrates \\
\hline $\mathrm{Zn} 2 \mathrm{p}$ & 1022.1 & 2.1 & 22.8 & $\mathrm{Zn}^{2+}$ \\
\hline $\mathrm{Al} 2 \mathrm{p}$ & 73.4 & 2.2 & 5.4 & $\mathrm{AlO}(\mathrm{OH})$ \\
\hline
\end{tabular}




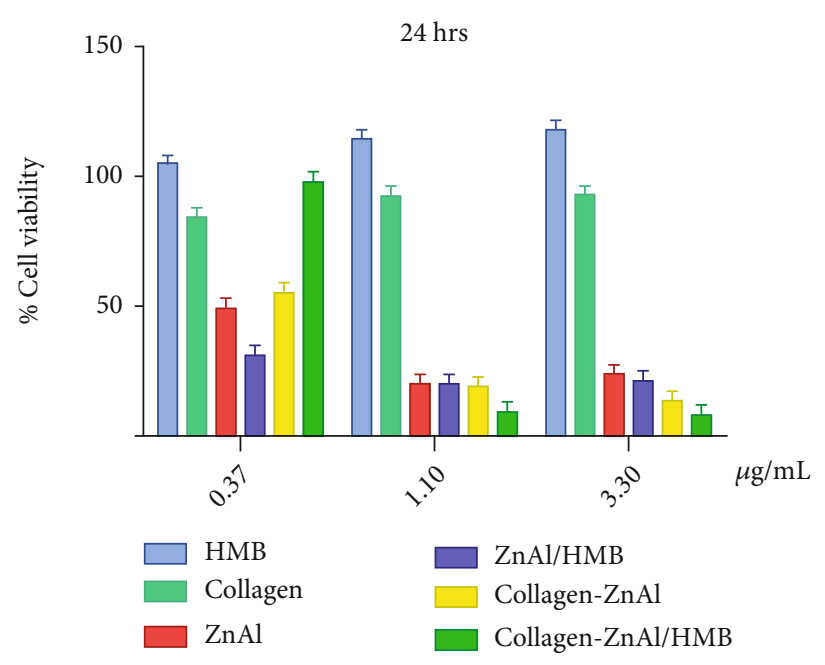

(a)

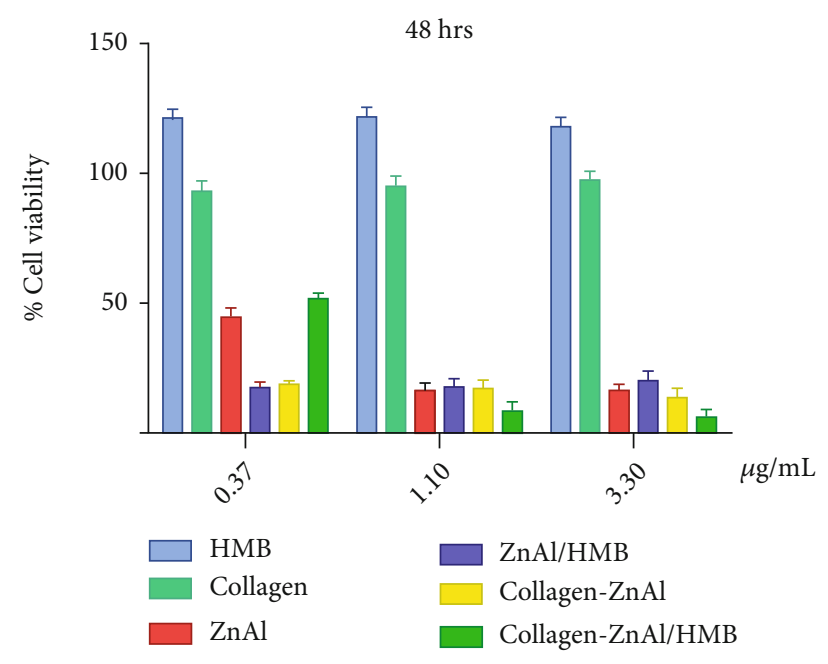

(b)

FIgURE 7: Cell viability of L6 cell line treated with LDH and hybrid compounds during (a) 24 and (b) $48 \mathrm{~h}$ of incubation, measured by watersoluble tetrazolium (WST-1) assay.

reflect that the molar composition, the target cell type, and cell fate are critical to their intracellular responses and degree of cytotoxicity.

One explanation for this observation could be related to the solubility of the synthesized materials [46]. Previously, it has been reported that at $\mathrm{pH} 6.8-7.4$, between 50 and $60 \%$ of $\mathrm{LDH}$ nanomaterial is found in dissolution at $8 \mathrm{~h}$ [49]. In supplementary material S3, we showed the LDH and the hybrid combinations are susceptible to degradation. Once upon dissolution, the materials can release $\mathrm{Al}^{3+}$ and $\mathrm{Zn}^{2+}$ ions from the composition of the sheets and exert a toxic effect, especially for the L6 cell line, as reported previously by Kane et al. and Song et al. [50, 51]. In addition, tetrazolium-based assays can be confounded by the presence of nanomaterials because it can interfere due to their optical capacity and absorption properties with the assay components [52-54], as well as interfere in the tetrazolium salts reduction by the presence of metal ions (such as $\mathrm{Zn}^{2+}$ ) [55, 56], which can contribute to false cytotoxicity results. Indeed, several works have highlighted this phenomenon when using tetrazolium salts and nanomaterials [53, 54, 56-58]. It represents a significant challenge since the in vitro viability tests constitute a part of high throughput screening strategies. Therefore, considering the limitations mentioned above, our results demonstrate that classical viability/cytotoxicity assays for nanomaterials are insufficient to assess their toxicologic effects on cell lines. It supports the necessity of complementing the cytotoxicity data with at least two or more independent assays depending on the cell line and the nanomaterial evaluated. Finally, all new nanomaterials must be carefully analyzed by different toxicity tests. It depends on the future applications because a single test does not evaluate complete physiological compartments.

\section{Conclusion}

In this work, we prepare a novel Collagen-ZnAl/HMB hybrid material by a coprecipitation method. This novel hybrid organic-inorganic material displays new properties based on a synergic effect of both inorganic layers and bioactive molecules. It is overcoming structural limitations of collagen by improving its reduced thermal stability due to the protection of $\mathrm{LDH}$ and increasing the bioavailability of HMB by its integration in their FA-HMB form. The present work achieves interesting inorganic-organic combination with a synergistic molecular level interface compared to separated components. It could be helpful to the fabrication of new controlled-release agents for delivery of bioactive compounds, showing excellent prospects.

Furthermore, it is necessary to investigate the toxicity through different levels, know their toxicity potential, and validate the reported toxicological test. The evaluation with a WST-assay is a limited tool to evaluate the toxicity potential from nanomaterials. Differents experimental approaches, especially in vivo assays, could reveal information about nanomaterials behavior in biological systems.

\section{Data Availability}

All data generated or analyzed during this study are included in this submitted article.

\section{Conflicts of Interest}

All the authors declare that they have no conflict/competing interest.

\section{Acknowledgments}

We are grateful that this research was partially funded by the PROSNI-Universidad de Guadalajara and Consejo Estatal de Ciencia y Tecnología (COECyTJAL) (8232-20219). Beatriz A. Andrade-Espinoza was supported by a scholarship from CONACyT-Mexico. The authors gratefully acknowledge the Materials Lab, Technical Sergio Oliva, and Ph. D. Martin Flores for the XRD and SEM equipment and Technical José 
Antonio Rivera Mayorga and Ph. D. Milton Oswaldo Vázquez Lepe for the XPS equipment from the Centro Universitario de Ciencias Exactas e Ingenierías from Universidad de Guadalajara, Jalisco, Mexico. Special thanks to M.C. David Tamayo Esquivel for providing language help and grammatical revision.

\section{Supplementary Materials}

Supplementary 1. Supplementary material S1: experiment to corroborate spectral variations induced by the HMB molecule.

Supplementary 2. Supplemental Figure S2: differential scanning calorimetry thermogram of (a) pure HMB and (b) collagen. Thermograms were recorded in the same differential scanning calorimeter and at the same experimental conditions.

Supplementary 3. Supplementary material S3: in vitro degradation assay of the $\mathrm{LDH}$ and hybrid compounds.

\section{References}

[1] S. J. Choi and Y. R. Kim, "Bioinspired layered nanoclays for nutraceutical delivery system," ACS Symposium Series, vol. 1143, pp. 207-220, 2013.

[2] Y. Zhao, H. Hu, X. Yang, D. Yan, and Q. Dai, "Tunable electronic transport properties of 2D layered double hydroxide crystalline microsheets with varied chemical compositions," Small, vol. 12, no. 33, pp. 4471-4476, 2016.

[3] A. Pucci, R. R. G. Bizzarri, and G. Ruggeri, "Polymer composites with smart optical properties," Soft Matter, vol. 7, no. 8, pp. 3689-3700, 2011.

[4] M. Bini, F. Q. I. Monteforte, I. Quinzeni, V. Friuli, L. Maggi, and G. Bruni, "Hybrid compounds for improving drugs solubility: synthesis, physico-chemical and pharmaceutical characterization of Nimesulide-LDH," Journal of Solid State Chemistry, vol. 272, pp. 131-137, 2019.

[5] F. M. Fernandes and H. C. S. Baradari, "Integrative strategies to hybrid lamellar compounds: an integration challenge," Applied Clay Science, vol. 100, pp. 2-21, 2014.

[6] A. F. da Silva, G. S. de Pádua, D. T. de Araújo, C. A. Vieira, and E. H. de Faria, "Immobilization of L-alanine into natural kaolinite via amidation catalyzed by boric acid for the development of biohybrid materials," Journal of Solid State Chemistry, vol. 287, p. 121332, 2020.

[7] S. S. Ray, D. Mosangi, and S. Pillai, "Layered double hydroxide-based functional nanohybrids as controlled release carriers of pharmaceutically active ingredients," The Chemical Record., vol. 18, no. 7-8, pp. 913-927, 2018.

[8] M. del Arco, A. Fernández, C. Martín, and V. Rives, "Solubility and release of fenbufen intercalated in $\mathrm{Mg}, \mathrm{Al}$ and $\mathrm{Mg}, \mathrm{Al}, \mathrm{Fe}$ layered double hydroxides (LDH): the effect of Eudragit ${ }^{\circledR} \mathrm{S}$ 100 covering," Journal of Solid State Chemistry, vol. 183, no. 12, pp. 3002-3009, 2010.

[9] A. U. Kura, M. Z. Hussein, S. Fakurazi, and P. Arulselvan, "Layered double hydroxide nanocomposite for drug delivery systems ; bio-distribution, toxicity and drug activity enhancement," Chemistry Central Journal, vol. 8, no. 1, p. 47, 2014.

[10] S. H. Hwang, Y. S. Han, and J. H. Choy, "Intercalation of functional organic molecules with pharmaceutical, cosmeceutical and nutraceutical functions into layered double hydroxides and zinc," Bulletin of the Korean Chemical Society, vol. 22, pp. 1019-1022, 2001.

[11] M. Silion, D. Hritcu, G. Lisa, and M. I. Popa, "New hybrid materials based on layered double hydroxides and antioxidant compounds. Preparation, characterization and release kinetic studies," Journal of Porous Materials, vol. 19, no. 3, pp. 267276, 2012.

[12] Y. Sun, Y. Zhou, X. Ye, J. Chen, and Z. Wang, "Fabrication and infrared emissivity study of hybrid materials based on immobilization of collagen onto exfoliated LDH," Materials Letters, vol. 62, no. 17-18, pp. 2943-2946, 2008.

[13] D. R. Martínez and G. G. Carbajal, "Hidróxidos dobles laminares: arcillas sintéticas con aplicaciones en nanotecnología," Avances en Quimica, vol. 7, pp. 87-99, 2012.

[14] H. N. Tran, C. C. Lin, and H. P. Chao, "Amino acidsintercalated $\mathrm{Mg} / \mathrm{Al}$ layered double hydroxides as dualelectronic adsorbent for effective removal of cationic and oxyanionic metal ions," Separation and Purification Technology, vol. 192, pp. 36-45, 2018.

[15] C. Ziegler, S. Werner, M. Bugnet et al., "Recent advances in the synthesis and application of layered double hydroxide (LDH) nano-sheets," American Chemical Society, vol. 112, no. 7, pp. 4124-4155, 2012.

[16] H. N. Tran, C. C. Lin, S. H. Woo, and H. P. Chao, "Efficient removal of copper and lead by $\mathrm{Mg} / \mathrm{Al}$ layered double hydroxides intercalated with organic acid anions: adsorption kinetics, isotherms, and thermodynamics," Applied Clay Science, vol. 154, pp. 17-27, 2018.

[17] H. N. Tran, D. T. Nguyen, G. T. le et al., "Adsorption mechanism of hexavalent chromium onto layered double hydroxides- based adsorbents: a systematic in-depth review," Journal of Hazardous Materials, vol. 373, pp. 258-270, 2019.

[18] L. Qin, S. Wang, R. Zhang, R. Zhu, X. Sun, and S. Yao, "Two different approaches to synthesizing $\mathrm{Mg}$-Al-layered double hydroxides as folic acid carriers," Journal of Physics and Chemistry of Solids, vol. 69, no. 11, pp. 2779-2784, 2008.

[19] E. F. Grosu and D. F. R. Simiuc, "Layered double hydroxides nanomaterials in biomedicine and (bio) sensing design," Biomedical Journal of Scientific \& Technical Research, vol. 2, no. 4, pp. 2747-2752, 2018.

[20] L. Gu, T. Shan, Y. Ma, F. R. Tay, and L. Niu, "Novel biomedical applications of crosslinked collagen," Trends in Biotechnology, vol. 37, no. 5, pp. 464-37491, 2019.

[21] A. Yasutake, S. Aisawa, S. Takahashi, H. Hirahara, and E. Narita, "Synthesis of biopolymer intercalated inorganiclayered materials: intercalation of collagen peptide and soybean peptide into $\mathrm{Zn}$-Al layered double hydroxide and layered zinc hydroxide," Journal of Physical and Chemistry of Solids, vol. 69, no. 5-6, pp. 1542-1546, 2008.

[22] D. Zdzieblik, S. Oesser, M. W. Baumstark, A. Gollhofer, and D. König, "Collagen peptide supplementation in combination with resistance training improves body composition and increases muscle strength in elderly sarcopenic men: a randomised controlled trial," The British Journal of Nutrition., vol. 114, no. 8, pp. 1237-1245, 2015.

[23] Y. Sun, Y. Zhou, Z. Wang, and X. Ye, "Fabrication of nanocomposites by collagen templated synthesis of layered double hydroxides assisted by an acrylic silane coupling agent," Applied Surface Science, vol. 255, no. 8, pp. 4497-4502, 2009. 
[24] M. D. Girón, J. D. Vílchez, S. Shreeram, and R. Salto, “ $\beta$ Hydroxy- $\beta$-methylbutyrate (HMB) normalizes dexamethasoneinduced autophagy-lysosomal pathway in skeletal muscle," PLoS One, vol. 10, no. 2, pp. e0117520-e0117520, 2015.

[25] M. Shirato, Y. Tsuchiya, T. Sato et al., "Effects of combined $\beta$-hydroxy- $\beta$-methylbutyrate (HMB) and whey protein ingestion on symptoms of eccentric exercise-induced muscle damage," Journal of the International Society of Sports Nutrition, vol. 13, no. 1, pp. 1-6, 2016.

[26] S. L. Nissen, P. J. Flakoll, and A. N. Abumrad, Method of promoting nitrogen retention in humans, U.S. Patent and Trademark Office, Washington, DC, 1994, Publication Number WO/1994/014429.

[27] D. J. Wilkinson, T. Hossain, M. C. Limb et al., "Impact of the calcium form of $\beta$-hydroxy- $\beta$-methylbutyrate upon human skeletal muscle protein metabolism," Clinical Nutrition, vol. 37, no. 6, pp. 2068-2075, 2018.

[28] J. M. Wilson, P. J. Fitschen, B. Campbell et al., "International society of sports nutrition position stand: beta-hydroxy-betamethylbutyrate (HMB)," Journal of the International Society of Sports Nutrition, vol. 10, no. 1, 2013.

[29] M. del Arco, A. Fernández, and C. V. R. Martín, "Solubility and release of fenbufen intercalated in $\mathrm{Mg}, \mathrm{Al}$ and $\mathrm{Mg}, \mathrm{Al}$, Fe layered double hydroxides (LDH): the effect of Eudragit $s$ S 100 covering," Journal of Solid State Chemistry, vol. 183, no. 12, pp. 3002-3009, 2010.

[30] R. Ortiz Castillo, M. E. Doumer, G. G. Carbajal Arízaga, A. Diaz Hernández, and C. Gomez Hermosillo, "Spectroscopic study of copper adsorption by chitosan and lignin composites containing layered double hydroxides," Journal of Electron Spectroscopy and Related Phenomena, vol. 226, pp. 1-8, 2018.

[31] A. Bhojaraj, J. Arulraj, M. R. Kolinjavadi, and M. Rajamathi, "Solvent-mediated and mechanochemical methods for anion exchange of carbonate from layered double hydroxides using ammonium salts," Omega, vol. 4, no. 22, pp. 20072-20079, 2019.

[32] S. B. Khan, K. A. Alamry, N. A. Alyahyawi, and A. M. Asiri, "Controlled release of organic-inorganic nanohybrid: cefadroxil intercalated Zn-Al-layered double hydroxide," International Journal of Nanomedicine, vol. Volume 13, pp. 3203-3222, 2018.

[33] M. Pavlovic, L. Li, F. Dits, Z. Gu, M. Adok-Sipiczki, and I. Szilagyi, "Aggregation of layered double hydroxide nanoparticles in the presence of heparin: towards highly stable delivery systems," RSC Advances, vol. 6, no. 20, pp. 16159-16167, 2016.

[34] T.-W. Sun, Y.-J. Zhu, and F. Chen, "Hydroxyapatite nanowire/ collagen elastic porous nanocomposite and its enhanced performance in bone defect repair $\dagger, "$ RSC Advances., vol. 8, no. 46, pp. 26218-26229, 2018.

[35] A. Kamyar, M. Khakbiz, A. Zamanian, M. Yasaei, and B. Yarmand, "Synthesis of a novel dexamethasone intercalated layered double hydroxide nanohybrids and their deposition on anodized titanium nanotubes for drug delivery purposes," Journal of Solid State Chemistry, vol. 271, pp. 144-153, 2019.

[36] K. Nava Andrade, P. Knauth, Z. López, G. A. Hirata, S. J. Guevara Martinez, and G. G. Carbajal Arízaga, "Assembly of folate-carbon dots in GdDy-doped layered double hydroxides for targeted delivery of doxorubicin," Applied Clay Science, vol. 192, p. 105661, 2020.

[37] G. Voicu, R. E. Geanaliu, C. D. Ghițulică, A. Ficai, A. M. Grumezescu, and C. Bleotu, "Synthesis, characterization and bioevaluation of irinotecan-collagen hybrid materials for biomedical applications as drug delivery systems in tumoral treatments," Central European Journal of Chemistry, vol. 11, no. 12, pp. 2134-2143, 2013.

[38] A. Viruete, G. G. Carbajal-Arízaga, R. Hernández Gutiérrez, A. R. Oaxaca Camacho, and J. Arratia-Quijada, "Passive targeting effect of Dy-doped LDH nanoparticles hybridized with folic acid and gallic acid on HEK293 human kidney cells and HT29 human cells," Journal of Nanoparticle Research, vol. 20, no. 12, pp. 1-10, 2018.

[39] Z. Dai, J. Deng, L. Ansaloni, S. Janakiram, and L. Deng, “Thinfilm-composite hollow fiber membranes containing amino acid salts as mobile carriers for $\mathrm{CO}_{2}$ separation," Journal of Membrane Science, vol. 578, pp. 61-68, 2019.

[40] G. G. C. Arizaga, J. E. F. . C. Gardolinski, W. H. Schreiner, and F. Wypych, "Intercalation of an oxalatooxoniobate complex into layered double hydroxide and layered zinc hydroxide nitrate," Journal of Colloid and Interface Science, vol. 330, no. 2, pp. 352-358, 2009.

[41] V. Samouillan, J. Dandurand, C. Lacabanne, R. J. Thoma, A. Adams, and M. Moore, "Comparison of chemical treatments on the chain dynamics and thermal stability of bovine pericardium collagen," Journal of Biomedical Materials Research A, vol. 64A, no. 2, pp. 330-338, 2003.

[42] E. Leikina, M. V. Mertts, N. Kuznetsova, and S. Leikin, “Type I collagen is thermally unstable at body temperature," Proceedings of the National Academy of Sciences of the United States of America, vol. 99, no. 3, pp. 1314-1318, 2002.

[43] M. Richetta, P. G. Medaglia, A. Mattoccia, A. Varone, and R. Pizzoferrato, "Layered double hydroxides : tailoring interlamellar nanospace for a vast field of applications," Journal of Material Sciences \& Engineering, vol. 6, no. 4, 2017.

[44] R. Gupta and H. Xie, "Nanoparticles in daily life: applications, toxicity and regulations," Journal of Environmental Pathology, Toxicology and Oncology, vol. 37, no. 3, pp. 209-230, 2018.

[45] E. Scarcello, A. Lambremont, R. Vanbever, P. J. Jacques, and D. Lison, "Mind your assays: misleading cytotoxicity with the WST-1 assay in the presence of manganese," PLoS One, vol. 15 , no. 4, 2020.

[46] S. J. Choi, J. M. Oh, T. Park, and J. H. Choy, "Cellular toxicity of inorganic hydroxide nanoparticles," Journal of Nanoscience and Nanotechnology, vol. 7, no. 11, pp. 4017-4020, 2007.

[47] J. Arratia-Quijada, S. Rivas-Fuentes, K. Saavedra, A. Lamas, and G. C. Arízaga, "Layered double hydroxide as a vehicle to increase toxicity of gallate ions against adenocarcinoma cells," Molecules, vol. 21, no. 7, p. 928, 2016.

[48] S. J. Choi and J. H. Choy, "Layered double hydroxide nanoparticles as target-specific delivery carriers: uptake mechanism and toxicity," Nanomedicine (London, England), vol. 6, no. 5, pp. 803-814, 2011.

[49] T.-H. Kim, J.-A. Lee, S.-J. Choi, and J.-M. Oh, "Polymer coated CaAl-layered double hydroxide nanomaterials for potential calcium supplement," International Journal of Molecular Sciences, vol. 15, no. 12, pp. 22563-22579, 2014.

[50] M. A. Kane, C. E. Kasper, and J. F. Kalinich, "The use of established skeletal muscle cell lines to assess potential toxicity from embedded metal fragments," Toxicology In Vitro, vol. 23, no. 2, pp. 356-359, 2009.

[51] W. Song, J. Zhang, J. Guo et al., "Role of the dissolved zinc ion and reactive oxygen species in cytotoxicity of $\mathrm{ZnO}$ nanoparticles," Toxicology Letters, vol. 199, no. 3, pp. 389397, 2010. 
[52] A. Almutary and B. J. S. Sanderson, "The MTT and crystal violet assays: potential confounders in nanoparticle toxicity testing," International Journal of Toxicology, vol. 35, no. 4, pp. 454-462, 2016.

[53] K. J. Ong, T. J. MacCormack, R. J. Clark et al., "Widespread nanoparticle-assay interference: implications for nanotoxicity testing," PLoS One, vol. 9, no. 3, p. e90650, 2014.

[54] I. L. Hsiao and Y. J. Huang, "Improving the interferences of methyl thiazolyl tetrazolium and IL-8 assays in assessing the cytotoxicity of nanoparticles," Journal of Nanoscience and Nanotechnology, vol. 11, no. 6, pp. 5228-5233, 2011.

[55] D. Granchi, G. Ciapetti, L. Savarino, D. Cavedagna, M. E. Donati, and A. Pizzoferrato, "Assessment of metal extract toxicity on human lymphocytes cultured in vitro," Journal of Biomedical Materials Research, vol. 31, no. 2, pp. 183-191, 1996.

[56] J. Fischer, M. H. Prosenc, M. Wolff, N. Hort, R. Willumeit, and F. Feyerabend, "Interference of magnesium corrosion with tetrazolium-based cytotoxicity assays," Acta Biomaterialia, vol. 6, no. 5, pp. 1813-1823, 2010.

[57] N. A. Monteiro-Riviere, A. O. Inman, and L. W. Zhang, "Limitations and relative utility of screening assays to assess engineered nanoparticle toxicity in a human cell line," Toxicology and Applied Pharmacology, vol. 234, no. 2, pp. 222-235, 2009.

[58] J. M. Wörle-Knirsch, K. Pulskamp, and H. F. Krug, "Oops they did it again! Carbon nanotubes hoax scientists in viability assays," Nano Letters, vol. 6, no. 6, pp. 1261-1268, 2006. 